\title{
TCOM \\ Toward an improved risk/crisis communication in this time of COVID-19 pandemic: a baseline study for Philippine local government units
}

\section{Reymund Flores and Xavier Venn Asuncion}

\begin{abstract}
This study mainly explores the communication preferences of the public; their level of trust in the government; and the factors affecting their risk/crisis perception amidst the COVID-19 pandemic. The key findings - derived from the data collected through an online survey and analysis using descriptive statistics, cross-tabulations, and Structural Equation Modeling (SEM), provide insights on how Local Government Units (LGUs) can improve their risk/crisis communication in this current health crisis. Among the key takeaways include the use of social media platforms, like Facebook, and native/local language for effective risk/crisis communication which may, consequently, foster trust building between the LGUs and the public.
\end{abstract}

Keywords

DOI

Health communication; Risk communication; Science communication: theory and models

https://doi.org/10.22323/2.19070209

Submitted: 30th June 2020

Accepted: 15th September 2020

Published: 14th December 2020

Introduction

Risk/crisis communication is among the most important aspects in managing and addressing the harmful and negative consequences of the COVID-19 pandemic. It involves responding to the public's need for information so that they can address the immediate and potential effects of a disaster or an emergency [Lachlan et al., 2016]. Within the context of COVID-19, this, among others, may include information about how they can protect themselves from the virus; how they can help in slowing down/preventing its transmission; the government's health and emergency response/strategies; number of confirmed cases/Persons Under Investigation (PUI)/Persons Under Monitoring (PUM); state of healthcare capacity; transmission scenarios, etc. These types of information can enable the public to make informed decisions with respect to protecting themselves or their communities from COVID-19, as well as facilitate civic engagement and collective action toward mitigating the current crisis and preventing future risks. 
In developing a risk/crisis communication plan/strategy for COVID-19, the initial step involves an assessment of the public's risk perception toward the disease [World Health Organization, 2020]. Risk perception is the subjective judgement of an individual about the nature and severity of a risk [Renner, Gamp et al., 2015]. In health decision-making, individuals are expected to navigate choices that involve weighing the risks and potential consequences over possible benefits of an action [Ferrer and Klein, 2015]. Citing the A/H1N1 virus or 'swine flu' outbreak in 2009, Renner and Reuter [2012] believed that the success of public health intervention programs is largely dependent on risk perception. Thus, as a major determinant of individual and collective protective action and behavior, risk perception was considered by the researchers in framing the model specification for this study. Information about the people's risk perception can serve as bases for coming up with risk/crisis communication messages to address misconceptions and negative or potentially detrimental perceptions.

Aside from risk perception, the public's communication preferences should also be assessed. This could serve as reference to identify how risk/crisis communication messages can be strategically delivered. It answers questions such as 'which communication channel to use?'; 'how frequent should information be disseminated?'; 'how to enable participation from the people?'; 'in what language should information be provided?' etc.

Methodology

This study aimed to provide baseline information that could guide Local Government Units (LGUs) in the Philippines to effectively communicate with their constituents amidst the current pandemic. This was done in two stages. The first stage involved an elicitation study which looked into how LGUs' use social media, specifically Facebook, to enable mutual trust and collective action during the COVID-19 crisis using the case of three highly urbanized cities in the country Quezon City, Iloilo City, and Davao City. These LGUs are from the three major island groups of the country - Luzon, Visayas, and Mindanao, respectively. Relatively, these LGUs have high population, and developed local economies. As such, it is most likely that social media is highly diffused in these localities which make them good case study areas. The elicitation study was performed through a rapid online assessment of the selected LGUs' Facebook posts since the imposition of the Enhanced Community Quarantine (ECQ) in the National Capital Region (NCR) from 12 March, a day after the World Health Organization (WHO) declared COVID-19 as a pandemic, until 4 April 2020. A total of 238, 233, and 196 posts from the respective Facebook accounts of Quezon City, Iloilo City, and Davao City were analyzed. These provided insights as to how LGUs currently communicate with their constituents. For each Facebook account, one person performed the content analysis. It is important to note that while the external validity of the findings from the elicitation study is limited, the results were used mainly as reference to design the data collection instrument for the next stage of this study.

The second stage of this study, through an online survey conducted from 28 April to 4 May 2020, draws upon the findings from the elicitation study and literature reviews. They served as bases to determine the variables used in assessing the public's risk perception and their communication preferences, including the model specification. The public's perception on the current crisis as well as how much they trust their LGUs' health crisis response and management strategies were 
likewise examined. The survey data were analyzed using descriptive statistics, cross-tabulations, and Structural Equation Modeling (SEM). The specific variables measured in this study, as derived from the elicitation study and review of related literature, along with their corresponding sources are summarized in Table 1 . The analysis of the goodness of fit of the SEM structure is shown in Table 8.

Table 1. Variables used and sources.

\begin{tabular}{|c|c|}
\hline Variables & Sources \\
\hline $\begin{array}{l}\text { Communication Preferences (of both the respondents and their LGUs) } \\
\text { - Type of information/communication being received } \\
\text { - Channels through which information/communication are being received } \\
\text { - How frequent information/communication are being received } \\
\text { - Presence of two-way communication channels for sending feedback/suggestions } \\
\text { - Language being used for communication }\end{array}$ & From Elicitation Study \\
\hline $\begin{array}{l}\text { Risk/Crisis Perception } \\
\text { - Perceived Benefits of Health and Safety Measures/Protocols } \\
\text { - Self-Protective Behavior (degree to which they practice self-protective behavior) } \\
\text { - Life Disruption (degree to which their lives were disrupted because of COVID-19) } \\
\text { - Perceived Susceptibility (to COVID-19) } \\
\text { - Perceived Severity of the Disease } \\
\text { - Perceived Severity of the Crisis }\end{array}$ & $\begin{array}{c}\text { Nicomedes and Avila [2020] } \\
\text { Kwok et al. [2020] }\end{array}$ \\
\hline $\begin{array}{l}\text { Public Trust } \\
\text { Perceived Effectiveness of LGU's Risk/Crisis Communication } \\
\text { Civic Engagement }\end{array}$ & From Elicitation Study \\
\hline
\end{tabular}

Using the survey instrument, respondents were asked questions which operationalize the variables framed by the researchers in their specified model (see Figure 1). The questionnaire used six-point discrete visual analog scale (DVAS) items that represent the respondents' COVID-19 risk perception and their assessments on the timeliness/frequency and effectiveness of their LGUs' COVID19 risk/crisis communication; level of trust toward their respective LGUs; perceived benefits of health safety protocols; and adoption of self-protective behavior practices. Reliability tests were performed for each summated variable using Cronbach's alpha set at 0.80 . The instrument used in this online survey obtained

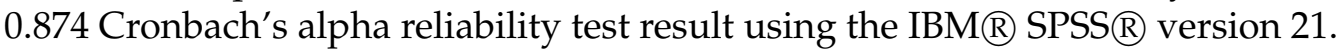

The results of both the Kolmogorov-Smirnov and Shapiro-Wilk tests, performed in all the data collected among items that operationalized the variables used in the specified model, revealed that the data-sets are not normally distributed $(\mathrm{P}=0.000)$. According to Hoyle and Panther [1995], maximum likelihood estimation approach tends to be good for non-normal data under some conditions such as excessive kurtosis and small sample sizes. Moreover, Olsson et al. [2000] suggested that when the sample size is less than 1000, like in this study, maximum likelihood is appropriate for SEM analysis. Hence, standardized maximum likelihood estimation was used in SEM analysis. SEM standardized path coefficients and

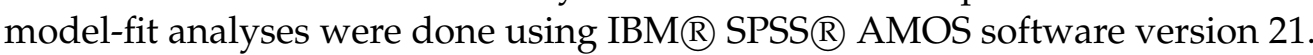






Figure 1. SEM Risk Perception and LGU-Risk/Crisis Communication Model Structure.

How LGUs communicate amidst the current pandemic
The fight against COVID-19 heavily relies on the government's role as civic enabler or its ability to enable strategic, systematic, and effective collective action toward addressing future risks and managing the current crisis. Collective action comprises both individual and group behaviors that contribute to slowing down the transmission of the disease, and mitigating its impacts. This could range from people's adherence to social distancing, proper hygiene, and quarantine protocols to resource/knowledge sharing through cross-sectoral partnerships and collaborations. Mutual trust is the foundation of collective action. The extent to which people are motivated to follow the government and make informed decisions to protect themselves, their families, and communities against the threats of a crisis depends on how much they trust public institutions [World Health Organization, 2017]. Lack of mutual trust could result to social unrests; incoherence in crisis and emergency response; and people relying on personal judgements or erroneous information which could potentially further aggravate crisis situations.

Integral to facilitating and fostering mutual trust and collective action is risk/crisis communication. This broadly involves effective and accurate dissemination and exchange of information about current and future risks, as well as the hazards and impacts before, during, and after a crisis [DiClemente and Jackson, 2017]. Individuals and groups across sectors may use this communication space to feed 
valuable ground information; suggest possible courses of action; and contribute something to ease the burden of the government in crisis management. Among communication channels that have become efficient tools for risk/crisis communication are social media platforms as they allow for a quick and effective way of communicating and engaging with large and diverse audiences [Substance Abuse and Mental Health Services Administration, 2019]. Moreover, they enabled individuals who were formerly passive receivers of risk information from traditional media to become active producers and disseminators. During outbreaks of infectious diseases - such as Ebola, MERS, and now COVID-19, communicators on social media played critical roles in the rapid production, sharing, and dissemination of information [Paek and Hove, 2017]. The use of social media platforms is especially useful in the Philippines where there is high level of diffusion, not just among the general public, but also in the government and public offices including LGUs [Alampay, Asuncion and delos Santos, 2018].

Based on the findings from the elicitation study, the following key information on how LGUs currently make use of social media, specifically Facebook, to communicate with their constituents amidst the COVID-19 pandemic were produced:

- Regular updates/reports on local crisis response and management. LGUs have provided regular updates/reports about their efforts, initiatives, and activities to address the current public health crisis. These comprised almost $60 \%$ to over $70 \%$ of the total number of Facebook posts during the three-week period covered in this study for the three selected LGUs. This was the highest among all identified types of information/communication. These posts generally include, among others, information about the LGUs' decontamination/disinfection efforts; relief distribution; and provision of transportation services, medical supplies and additional support to frontliners. Also included were updates related to public issuances on policies, guidelines, and protocols adopted by the LGUs in the implementation of the enhanced community quarantine; monitoring of local prices; social distancing protocols; curfew hours; and liquor ban. These regular updates/reports help in building and maintaining mutual trust as they provide evidence that the LGU is doing its best to manage the crisis situation.

- Promotion of Self-Protective Behaviors. LGUs have also focused on sharing large amounts of information from various sources about the nature of the COVID-19 virus and precautionary measures to prevent being infected with the disease. These were usually in the form of educational and informative videos, infographics, and photos answering questions like what the virus is; what are the symptoms; how it spreads; and what can be done to protect yourself and prevent its spread. These posts help people become more aware of the risks posed by COVID-19 and make informed decisions to better prepare themselves against the virus. These further help the people understand the rationale behind why certain policies, and measures such as social distancing protocols and ECQ, were put in place.

- Encouraging Civic Engagement. Within the context of the COVID-19 crisis, civic engagement involves active participation and support of people and groups in addressing the impacts and managing risks by sharing, for example, their 
resources, skills, and knowledge to the government or with others, in general. The results of the elicitation study suggest that LGUs initiate civic engagement in Facebook through posts that call for support and donations from private individuals and firms. What further foster civic engagement are the appreciation posts for donations, contributions, and other forms of support. These were usually in the form of photos showing who were the donors/contributors and how they helped along with a caption expressing the LGU's gratitude.

- Regular updates/reports on local crisis situation. These types of posts in the LGUs' Facebook pages include information about the number of confirmed COVID-19 cases; patients who have died or were able to recover from the disease; Patients Under Investigation (PUIs); and Patients Under Monitoring (PUM). These help create situational awareness among people and communities. Consequently, these could drive and influence collective action because the public will be more motivated to practice self-protective behaviors if they know the degree of the risks to which they are exposed. At the same time, they could also encourage civic engagement as the public becomes more aware of the extent of the current crisis situation within their respective localities.

- Addressing misinformation, fake news and other issues about the crisis. While social media has provided opportunities for effective communication, as an unregulated space, it has also led to the proliferation of misinformation and fake news. This is particularly a concern during a crisis when there is higher media dependency and the spread of information is faster because of people's heightened emotions. Misinformation and fake news are dangerous during a crisis as they could erode mutual trust, and misdirect collective action. It is in these situations that the role of the government in providing accurate, timely, and reliable information comes into play. As such, LGUs, as risk/crisis communicators, should focus on trust building during public health crisis. The more trustworthy the message and source is, the more that the public will receive the message positively [Tormala and Clarkson, 2008]. To counter misinformation and fake news, social media can also be used to immediately address and clarify other issues that could potentially exacerbate or worsen the current crisis situation. Based on the case studies, these posts are usually in the form of clarificatory statements that are sometimes accompanied by photos showing the wrong information; fake news; or the issue being clarified.

Toward an improved risk/crisis communication
This section enumerates and discusses the key takeaways from the second stage of this study. It is important to note that the generalizability of the findings is limited to the obtained sample from the online survey. Nevertheless, these findings can serve as a guide for LGUs to effectively communicate with their constituents. The following is a summary of the respondents' profile: 
- Geographic. A total of 250 responses were collected from 96 cities/municipalities in 31 provinces and 15 regions of the country. Most responses came from the National Capital Region (NCR, 31\%), Zamboanga del Norte $(17 \%)$ and Iloilo (11\%), comprising almost $60 \%$ of the overall respondents.

- Age Group. Most (76\%) of the respondents were from age groups 18-29 (42\%) and $30-39(34 \%)$. The rest belong to age groups $40-49(14 \%), 50-59(9 \%)$, and 60 and above $(1 \%)$.

- Sex. Most or $64 \%$ of the respondents were female while $36 \%$ are male respondents.

- Highest Educational Attainment. Majority (56\%) of the respondents were college graduates. A relatively high number of responses also came from those who have completed graduate studies at $34 \%$.

- Occupation (status prior to ECQ). Most (78\%) of the respondents were employed before the implementation of ECQ. Others were students $(9 \%)$, and self-employed (7\%). Only $6 \%$ was unemployed.

\section{Communication preferences}

Social media (such as Facebook) is the primary channel for receiving/seeking information. Majority (57\%) of the respondents said that they usually receive/seek risk/crisis information from their LGUs through their social media accounts and pages, e.g. Facebook. Others usually receive/seek them from television (18\%); online news articles (8\%); government websites $(7 \%)$; community announcements (4\%); and mobile messaging applications (2\%).

Preference for other communication channels of people aged 40 and above. Majority (62\%) of the respondents between 18-39 years old said that they usually access information through social media; but for those 40 years old and above, only $41 \%$ prefer social media over other communication channels such as Television; Radio; Online News Articles; Government Websites; and Mobile Messaging Applications (see Table 2).

Table 2. Preferred communication channel by age group.

\begin{tabular}{|ccc|}
\hline Age Group & Social Media & Other Communication Channels \\
\hline $18-39$ Years Old & $62 \%$ & $38 \%$ \\
40 Years Old and Above & $41 \%$ & $59 \%$ \\
\hline
\end{tabular}

People access information once or more daily. Around 35\% of the respondents access information once, while $24 \%$ of them access information more than once daily from their LGUs. At $59 \%$, this comprises the majority of the respondents. Based on the survey responses, the most frequently/timely disseminated types of information that the public receives from their LGUs are updates/reports on local COVID-19 situation; updates/reports on COVID-19 response/management; information on safety measures against COVID-19; and appreciation posts for donors/contributors. 
Frequent and timely communication. The results of the simultaneous regression and path analysis showed that when LGUs produce more and timely information related to the present health crisis, it is more likely that there will be positive public perception on their risk/crisis communication effectiveness (see Figure $1 \&$ Table 7). The cross tabulation between frequency and timeliness of communication and perceived effectiveness of an LGU's risk/crisis communication also supports these results. Individuals who were receiving risk/crisis information once or more daily from their LGUs perceived that their LGUs' risk/crisis communication are moderately $(\bar{x}=4.17)$ or highly $(\bar{x}=4.88)$ effective. Those who were receiving risk/crisis information only once a day or once a week perceived that their LGUs' risk/crisis communication strategies are less effective $(\bar{x}=3.31$ to 3.33$)$ (see Table 3).

Table 3. Frequency and timeliness of communication \& perceived effectiveness of an LGU's risk/crisis communication (mean rating).

\begin{tabular}{|l|c|}
\hline Frequency and Timeliness of Communication & $\begin{array}{c}\text { Perceived Effectiveness of the LGU's } \\
\text { Risk/Crisis Communication } \\
\text { (Mean Rating) }\end{array}$ \\
\hline More than once a day & 4.88 \\
Once a day & 4.17 \\
More than once a week & 3.33 \\
Once a week & 3.31 \\
\hline
\end{tabular}

The following is the list of range and the corresponding description to describe perceived effectiveness of the LGU's COVID-19 Risk/Crisis Communication:

1.00-1.83 - Extremely Not Effective

1.84-2.66 - Slightly Not Effective

2.67-3.49 - Less Effective

3.50-4.32 - Moderately Effective

4.33-5.15 - Highly Effective

5.16-6.00 - Extremely Effective

Financial updates/reports related to COVID-19 response. Relative to other types of information, the LGUs that provided the most and timely financial updates/reports related to COVID-19 response received the highest effectiveness perception $(\bar{x}=4.90)$ (see Table 4 ) from the respondents on their risk/crisis communication. However, this type of updates/reports is the least frequently/timely released by LGUs based on the responses.

Presence of interactive communication. More than half (52\%) of the respondents said that their LGUs use two-way communication channels where they could send feedback and suggestions; or there are means for interaction. Most (72\%) of them are able to do these through social media platforms, either by sending a direct message to their LGUs' social media accounts (usually through Facebook) or by posting a comment on their posts. For others $(28 \%)$, they said that they are able to provide feedback; send suggestions; or interact with their LGUs through their LGU's official website; by going directly to the LGU offices; or calling the LGU's mobile/landline numbers/hotlines. The results of the study also suggest that people are more likely to associate effectiveness of risk/crisis communication when two-way communications channels are present. 
Table 4. Type of information/communication being received \& perceived effectiveness of an LGU's risk/crisis communication (mean rating).

\begin{tabular}{|l|c|}
\hline \multicolumn{1}{|c|}{ Type of Information/Communication Being Received } & $\begin{array}{c}\text { Perceived Effectiveness of an LGU's } \\
\text { Risk/Crisis Communication } \\
\text { (Mean Rating) }\end{array}$ \\
\hline Financial updates/reports related to COVID-19 response & 4.90 \\
Clarification of fake news/misinformation/issues & 4.60 \\
Updates/Reports on COVID-19 response/management & 4.47 \\
Updates/Reports on Local COVID-19 situation & 4.45 \\
Appreciation posts for donors/contributors & 4.40 \\
Call for donations/contributions & 4.39 \\
Information dissemination on how to protect from COVID-19 & 4.36 \\
\hline
\end{tabular}

The following is the list of range and the corresponding description to describe perceived effectiveness of the LGU's COVID-19 Risk/Crisis Communication:

1.00-1.83 - Extremely Not Effective

1.84-2.66 - Slightly Not Effective

2.67-3.49 - Less Effective

3.50-4.32 - Moderately Effective

4.33-5.15 - Highly Effective

5.16-6.00 - Extremely Effective

Use of native/local language. Most of the respondents (40\%) answered that their LGU communicates with them using their native/local language, 32\% said that their LGU uses Filipino, the country's national language, while $24 \%$ said that their LGU gives information to them using the English language. The rest answered that their LGU uses a combination of either English and Filipino or English and native/local language (4\%). While the findings suggest that, generally, the use of any language can lead to a higher risk/crisis communication effectiveness perception, it is argued that the use of native/local language can further increase the public's effectiveness perception on the LGU risk/crisis communication (see Table 5).

Table 5. Language being used for communication \& perceived effectiveness of an LGU's risk/crisis communication (mean rating).

\begin{tabular}{|l|c|}
\hline Language Being Used for Communication & $\begin{array}{c}\text { Perceived Effectiveness of an LGU's } \\
\text { Risk/Crisis Communication } \\
\text { (Mean Rating) }\end{array}$ \\
\hline Native/Local Language & 4.19 \\
English & 4.02 \\
Filipino (National Language) & 3.54 \\
\hline
\end{tabular}

The following is the list of range and the corresponding description to describe perceived effectiveness of the LGU's COVID-19 Risk/Crisis Communication:

$1.00-1.83$ - Extremely Not Effective

$1.84-2.66$ - Slightly Not Effective

2.67-3.49 - Less Effective

3.50-4.32 - Moderately Effective

4.33-5.15 - Highly Effective

5.16-6.00 - Extremely Effective 
Wright, Bolger and Rowe [2002] explained that risk perception can be reflective of the information regarding personal experiences and considers how people, specifically laypeople, construe risk. It can also be influenced by what information is most salient or available to them [Tversky and Kahneman, 1973]. For example, individuals perceive risk to be higher when someone in their family or community has been infected by the virus [Chen and Kaphingst, 2011]. Information about the individual's susceptibility to the disease also plays a role in the formation of risk perception. Risk perception likewise tends to be higher when health threat is seen as uncontrollable or dreaded [Slovic, 1987]. Distress and anxiety that cause life disruptions are likewise associated with higher risk perception [Mathur and Levy, 2013].

Generally, the results of the survey support the theoretical assumptions developed from the key findings of the elicitation study about how LGUs can use social media platforms, such as Facebook, to enable mutual trust and collective action where it was discussed how integral risk/crisis communication is in facilitating and fostering mutual trust. According to Turcotte et al. [2015], when people believe that the information came from quality sources, they are more likely to trust this information. DiClemente and Jackson [2017] explained that for risk/crisis communication to be effective it should broadly involve accurate and timely dissemination and exchange of information about current and future risks, hazards and impacts before, during, and after a crisis. Thus, to gain public trust to their health policy actions, LGUs must see to it that they are doing their risk/crisis communication effectively, with credibility, and clearly understood by the public.

Below are specific insights from the findings of the study on risk/crisis perception and public trust:

- Generally high risk/crisis perception. All the factors measured to assess the respondents' risk/crisis perception got high mean scores within the six-point DVAS (4-5.41). This suggests a generally high risk/crisis perception among the respondents.

- Factors involved in risk/crisis perception formation: perceived severity of the crisis; life disruption; perceived severity of the disease; and perceived susceptibility. The results of the confirmatory factor analysis (CFA) revealed that perceived severity of the crisis, life disruption, perceived severity of the disease, and perceived susceptibility have significant contributions in the formation of the latent variable - risk perception, in the context of the COVID-19 public health crisis. It further showed that life disruption and the person's perception on the severity of the [health] crisis contribute more in the formation of their risk perception. The results of the CFA suggest that individual risk perception tends to be higher as their perception based on these factors increases (see Table 6 \& Figure 1).

- Higher perceived effectiveness of LGU-risk/crisis communication enables trust building. The simultaneous regression and path analysis to the model have shown that LGU-risk/crisis communication must be effective to improve public trust (see Figure 1 \& Table 7). This is consistent with the idea of van Zoonen and van der Meer [2015] that a higher public perception on the 
Table 6. Mean rating of risk/crisis perception variables.

\begin{tabular}{|l|c|}
\hline Risk/Crisis Perception Variables & Mean Rating \\
\hline Perceived Severity (of the crisis) & 5.42 \\
Disruption (of lives) & 4.81 \\
Perceived Susceptibility & 4.03 \\
Perceived Severity (of the disease) & 4.01 \\
\hline
\end{tabular}

effectiveness of risk/crisis communication implies credibility in terms of content or source.

Table 7. Results of the standardized regression coefficient analysis (Maximum Likelihood Estimates) to the SEM model (including the CFA).

\begin{tabular}{|c|c|c|c|c|c|c|c|}
\hline & & & Standardized $\beta$ & S.E. & C.R. & $\mathbf{P}$ & Label \\
\hline $\begin{array}{l}\text { Perceived Effectiveness of } \\
\text { LGU's COVID-19 Risk/ } \\
\text { Crisis Communication }\end{array}$ & $\longleftarrow$ & $\begin{array}{l}\text { Frequency/Timeliness of } \\
\text { LGU's COVID-19 Risk/ } \\
\text { Crisis Communication }\end{array}$ & .56 & .056 & 10.603 & $* * *$ & Significant Path \\
\hline Public Trust & $\longleftarrow$ & $\begin{array}{l}\text { Perceived Effectiveness of } \\
\text { LGU's COVID-19 Risk/ } \\
\text { Crisis Communication }\end{array}$ & .85 & .032 & 25.065 & $* * *$ & Significant Path \\
\hline $\begin{array}{l}\text { Perceived Benefits } \\
\text { of Health and Safety } \\
\text { Measures/Protocols }\end{array}$ & $\longleftarrow$ & Risk Perception & .21 & .079 & 2.434 & .015 & Significant Path \\
\hline $\begin{array}{l}\text { Perceived Benefits } \\
\text { of Health and Safety } \\
\text { Measures/Protocols }\end{array}$ & $\longleftarrow$ & Public Trust & .27 & .020 & 4.491 & $* * *$ & Significant Path \\
\hline Self-Protective Behavior & $\longleftarrow$ & $\begin{array}{l}\text { Perceived Benefits } \\
\text { of Health and Safety }\end{array}$ & .24 & .093 & 3.865 & $* * *$ & Significant Path \\
\hline Perceived Susceptibility & $\longleftarrow$ & Risk Perception & .32 & .264 & 2.809 & .005 & Significant Path \\
\hline Disruption & $\longleftarrow$ & Risk Perception & .60 & .239 & 5.437 & $* * *$ & Significant Path \\
\hline $\begin{array}{l}\text { Perceived Severity of the } \\
\text { Disease }\end{array}$ & $\longleftarrow$ & Risk Perception & .46 & .190 & 3.844 & $* * *$ & Significant Path \\
\hline $\begin{array}{l}\text { Perceived Severity of the } \\
\text { Crisis }\end{array}$ & $\longleftarrow$ & Risk Perception & .63 & .142 & 5.437 & $* * *$ & Significant Path \\
\hline
\end{tabular}

- Public trust and risk perception have implications to the public's perception on the benefits of the health and safety measures/protocols imposed. Tormala and Clarkson [2008] underscored that demonstrating credibility is necessary to foster trust in order to increase the effect of the message. The simultaneous regression and path analysis to the model affirms their argument where a higher-level of public trust to the LGU will more likely lead to positive perception on the benefits of the health and safety measures/protocols being implemented. Moreover, it reveals that the greater the perceived risk for one's own health, the higher the chance that the individual will appreciate and develop positive perception to the benefits of the health and safety measures/protocols (see Figure 1 \& Table 7).

- Observance of self-protective behavior will more likely happen when the public believes that safety measures/protocols are beneficial to them. The path analysis to the model provided statistical evidence that for the respondents, perceived 
benefits of health and safety measures/protocols could more likely affect their decision to observe self-protective behaviors. This implies that in this time of health crisis where risk perception increases, the public will more likely to believe in the benefits of health and safety policies, provided, that there is high level of public trust in their LGUs. When the public perceives that these health and safety measures/protocols are beneficial to them they will more likely be motivated to observe these self-protective actions (see Figure 1 \& Table 7).

Table 8. Fit index analyses of the SEM model.

\begin{tabular}{l|ccc|}
\hline Measures of Fit & Recommended Value & Value of the Model & Label \\
\hline RMSEA & $<0.80$ & 0.07 & Good Fit \\
NFI & $\geq 0.90$ & 0.90 & Good Fit \\
TLI & $\geq 0.90$ & 0.93 & Good Fit \\
CFI & $\geq 0.95$ & 0.95 & Good Fit \\
\hline \multicolumn{4}{|l}{ RMSEA - Root Mean Square Error of Approximation } \\
NFI - Normative Fit Index \\
TLI - Tucker Lewis Index \\
CFI - Comparative Fit Index
\end{tabular}

Recommendations While the external validity of the findings is limited, they nonetheless reflect the value of what insights can be generated from assessing the public's risk/crisis perception and communication preferences. These can be used to determine the content and the manner by which risk/crisis communication messages can be effectively delivered. Aside from the findings, the following are other strategies and ways that LGUs could consider. These recommendations, summarized according to the emerging themes, were derived from the elicitation study findings, and survey responses.

- Maximize the use of social media through more interaction/engagement with users. Social media platforms like Facebook can be used to more efficiently and actively disseminate COVID-19 related information. Moreover, it can be used to collect feedback and suggestions, or interact with the public by way of creating a Facebook group or through live chatting and doing online polls. This is actually one of the features of social media that makes it an effective channel for risk/communication [Farha, 2015]. However, key findings in the elicitation study suggests that LGUs have not been taking advantage of this feature. Many comments from the LGUs' social media posts were queries, concerns and suggestions about how the LGU is responding to the crisis. Responding to these queries, concerns, and suggestions could boost public trust.

- Use of multiple means/channels for communication. Use of more means/channels for communication can enable LGUs to reach more people as different platforms have varying levels of accessibility to the public. Risk/Crisis communication is not limited to social media use. Maximizing the potential of establishing a good working relationship among local radio and television networks in facilitating and disseminating risk/crisis information could 
increase public access to real time information in crisis situations, particularly this time of pandemic. Another strategy for communication is the use of mobile messaging or blast texting and establishing 24-hour hotline services, help desks, and information centers.

- More nuanced and understandable reports/updates on local crisis situation. Risk/Crisis communication messages are only conveyed successfully if they are clearly understood by the public [Substance Abuse and Mental Health Services Administration, 2019]. Use of foreign language, and technical terms could distort how people understand these messages. Thus, LGUs should be more consistent in presenting data; use infographics; use of native language, more understandable terms, and non-technical terms; be more transparent in their use of local funds; and use reliable sources in disseminating information. The clearer the reports/updates on local crisis situation are, the more people are aware of their risk exposure and the gravity of the current crisis situation. For example, in Quezon City, the numbers regarding COVID-19 cases are broken down per barangay, the lowest unit of local government in the Philippines. This is useful because the people in barangays with relatively higher number of confirmed COVID-19 cases will be more vigilant and persuaded to practice self-protective behaviors. LGUs could also include situational reports about their current healthcare capacity and availability of resources. This can guide civic engagement as people will be able to identify entry points for support and assistance.

- Information sharing and exchanges among neighboring LGUs in their social media pages. Findings from the elicitation study suggest that policy regulations and restrictions are oftentimes implemented in varying degrees among different LGUs. Those residing within the LGU-boundaries are affected by the differences in policies which could result to public confusion. The propensity of such confusion can be reduced if LGUs will also share information about the measures adopted by neighboring LGUs.

- Making use of public officials' social media pages. Evidently, the use of multiple social media pages would result to higher reach in disseminating risk/crisis communication messages. Also, based on the case studies, the Facebook pages of Local Chief Executives (LCEs)/Mayors tend to have higher following (likes and followers) and higher post engagements (shares and reacts) than the official pages of the LGUs.

- Enhance the involvement of Barangays. The LGUs should ensure the involvement of barangays and recognize their essential role in collaborating with the communities to collect insights and suggestions and to achieve greater inclusivity in their COVID-19 responses. Barangays are practically missing when it comes to disseminating timely information and were not particularly useful in collecting ground level information. Their involvement shall not just be limited to disseminating information, but also in verifying information from the ground. Inclusion of barangays in the risk/crisis communication structure of the LGU could result to a timelier information exchanges and dissemination between the LGU and the communities. This can be an important strategy that LGUs should adopt in order to prevent the proliferation of unreliable information circulating among communities - from confusion and rumors over the government's financial and social assistance or what Filipinos call "ayudas" to presence of COVID-19 
cases in certain areas. LGUs should likewise ensure that their risk/communication plans include someone/a team who will coordinate on the reporting of Barangays on COVID-19 related information.

- Develop a local risk/crisis communication plan. To operationalize and integrate the findings of this study, and the aforementioned recommendations, LGUs should develop their own local risk/crisis communication plans. This generally involves the establishment of local risk/crisis communication teams with designated and trained people or groups who will collect and analyze the necessary data to develop the plan and will handle all of the LGUs' communication activities during the COVID-19 crisis.

\section{Conclusion}

Risk/Crisis Communication is an integral component in the LGU's crisis response and management. It does not only involve the question 'if it is being done', but also 'if it is being done right'. This requires risk/crisis communicators, generally the LCEs, to have the skill and will in setting their respective LGUs to become enablers of mutual trust and collective action in health emergency situations. Their ability to respond to the demands of more practicable policy choices and in the evolving concerns of their constituencies can become defining factors for mutual trust building among people, business firms, and other social sectors. The findings from this study can help LGUs in this regard when they decide what and how to communicate with the public during this time of health crisis.

\section{References}

Alampay, E. A., Asuncion, X. V. and delos Santos, M. (2018). 'Management of social media for disaster risk reduction and mitigation in Philippine local government units'. In: Proceedings of the 11th International Conference on Theory and Practice of Electronic Governance - ICEGOV'18. ACM Press. https://doi.org/10.1145/3209415.3209452.

Chen, L. S. and Kaphingst, K. A. (2011). 'Risk perceptions and family history of lung cancer: differences by smoking status'. Public Health Genomics 14 (1), pp. 26-34. https://doi .org/10.1159/000294151.

DiClemente, R. J. and Jackson, J. M. (2017). 'Risk communication'. In: International encyclopedia of public health. 2nd ed. The Netherlands: Elsevier, pp. 378-382. https://doi org/10.1016/b978-0-12-803678-5.00389-1.

Farha, M. A. (2015). 'Social media and crises communication management'. In: Communication management course paper. U.S.A.: Indiana University of Pennsylvania.

Ferrer, R. A. and Klein, W. M. P. (2015). 'Risk perceptions and health behavior'. Current Opinion in Psychology 5, pp. 85-89. https://doi.org/10.1016/j.copsyc.2015.03.012.

Hoyle, R. H. and Panther, A. T. (1995). 'Writing about structural equation models'. In: Structural equation modeling: concepts, issues and applications. Ed. by R. H. Hoyle. Thousand Oaks, CA, U.S.A.: Sage.

Kwok, K. O., Li, K. K., Chan, H. H. H., Yi, Y. Y., Tang, A., Wei, W. I. and Wong, S. Y. S. (2020). 'Community responses during the early phase of the COVID-19 epidemic in Hong Kong: risk perception, information exposure and preventive measures'. Emerging Infectious Diseases 26 (7), pp. 1575-1579. https://doi.org/10.3201/eid2607.200500. 
Lachlan, K. A., Spence, P. R., Lin, X., Najarian, K. and Del Greco, M. (2016). 'Social media and crisis management: CERC, search strategies and Twitter content'. Computers in Human Behavior 54, pp. 647-652. https://doi.org/10.1016/j.chb.2015.05.027.

Mathur, S. and Levy, M. (2013). 'Lung cancer risk perception and distress: dfference by smoking status and role of physical activity and race among U.S. population'. Epidemiology, Biostatistics and Public Health 10 (2), e8839. https://doi.org/10.2427/8839.

Nicomedes, C. J. C. and Avila, R. M. A. (2020). 'An analysis on the panic during COVID-19 pandemic through an online form'. Journal of Affective Disorders 276, pp. 14-22. https://doi.org/10.1016/j.jad.2020.06.046.

Olsson, U. H., Foss, T., Troye, S. V. and Howell, R. D. (2000). 'The performance of ML, GLS and WLS estimation in structural equation modeling under conditions of misspecification and nonnormality'. Structural Equation Modeling: A Multidisciplinary Journal 7 (4), pp. 557-595. https://doi.org/10.1207/s15328007sem0704_3.

Paek, H. and Hove, T. (2017). 'Risk perceptions and risk characteristics'. Communication Theory, Health and Risk Communication. https://doi.org/10.1093/acrefore/9780190228613.013.283.

Renner, B., Gamp, M., Schmälzle, R. and Schupp, H. T. (2015). 'Health risk perception'. In: International encyclopedia of the social \& behavioral sciences. Ed. by J. Wright. 2nd ed. Vol. 10. The Netherlands: Elsevier, pp. 702-709. https://doi.org/10.1016/b978-0-08-097086-8.14138-8.

Renner, B. and Reuter, T. (2012). 'Predicting vaccination using numerical and affective risk perceptions: the case of A/H1N1 influenza'. Vaccine 30 (49), pp. 7019-7026. https://doi.org/10.1016/j.vaccine.2012.09.064.

Slovic, P. (1987). 'Perception of risk'. Science 236 (4799), pp. 280-285. https://doi.org/10.1126/science.3563507.

Substance Abuse and Mental Health Services Administration (2019). Communicating in a crisis: risk communication guidelines for public officials. SAMHSA publication no. PEP19-01-01-005. Rockville, MD, U.S.A.: Substance Abuse and Mental Health Services Administration.

URL: https://store.samhsa.gov/product/communicating-crisis-risk-comm unication-guidelines-public-officials/pep19-01-01-005.

Tormala, Z. L. and Clarkson, J. J. (2008). 'Source trustworthiness and information processing in multiple message situations: a contextual analysis'. Social Cognition 26 (3), pp. 357-367. https://doi.org/10.1521/soco.2008.26.3.357.

Turcotte, J., York, C., Irving, J., Scholl, R. M. and Pingree, R. J. (2015). ‘News recommendations from social media opinion leaders: effects on media trust and information seeking'. Journal of Computer-Mediated Communication 20 (5), pp. 520-535. https://doi.org/10.1111/jcc4.12127.

Tversky, A. and Kahneman, D. (1973). 'Availability: a heuristic for judging frequency and probability'. Cognitive Psychology 5 (2), pp. 207-232. https://doi.org/10.1016/0010-0285(73)90033-9.

van Zoonen, W. and van der Meer, T. (2015). 'The importance of source and credibility perception in times of crisis: crisis communication in a socially mediated era'. Journal of Public Relations Research 27 (5), pp. 371-388. https://doi.org/10.1080/1062726x.2015.1062382.

Walaski, P. (2011). Risk and crisis communication: methods and messages. New York, NY, U.S.A.: Wiley. 
World Health Organization (2017). Communicating risk in public health emergencies: a WHO guideline for emergency risk communication (ERC) policy and practice.

URL: https: //www . who . int/risk-communication/guidance/download/en/.

- (2020). RCCE action plan guidance: COVID-19 preparedness $\mathcal{E}$ response.

URL: https://www . who. int/publications-detail/risk-communication-andcommunity-engagement-(rcce)-action-plan-guidance.

Wright, G., Bolger, F. and Rowe, G. (2002). 'An empirical test of the relative validity of expert and lay judgments of risk'. Risk Analysis 22 (6), pp. 1107-1122. https://doi.org/10.1111/1539-6924.00276.

Authors

Reymund B. Flores (Doctor of Public Administration, University of the Philippines Diliman) is an Assistant Professor of Politics and Public Administration in the Department of Social Sciences at West Visayas State University. His research interests include disaster risk management planning, risk/crisis communication, collaborative governance, East and Southeast Asian studies, public policy, and state-civil society engagements. E-mail: greatmund@gmail.com.

Xavier Venn A, Asuncion (MSc in Urban Management and Development, Erasmus University Rotterdam) is a University Researcher at the Center for Local and Regional Governance (CLRG-NCPAG), University of the Philippines. He works on projects related to Disaster Risk Reduction-Climate Change Adaptation (DRR-CCA) such as climate finance, risk insurance and social media use for disaster risk reduction. E-mail: xaasuncion1@upd.edu.ph.

\section{How to cite}

Flores, R. and Asuncion, X. V. (2020). 'Toward an improved risk/crisis communication in this time of COVID-19 pandemic: a baseline study for Philippine local government units'. JCOM 19 (07), A09. https:/ / doi.org/10.22323/2.19070209. 